\title{
Optimum Availability of Standalone Photovoltaic Power Systems for Remote Housing Electrification
}

\author{
Tamer Khatib and Wilfried Elmenreich \\ Institute of Networked \& Embedded Systems/Lakeside Labs, University of Klagenfurt, P.O. Box B10a.2, 9020 Klagenfurt, Austria \\ Correspondence should be addressed to Tamer Khatib; tamer_khat@hotmail.com
}

Received 5 January 2014; Revised 15 April 2014; Accepted 29 April 2014; Published 8 May 2014

Academic Editor: Hongxing Yang

Copyright ( 2014 T. Khatib and W. Elmenreich. This is an open access article distributed under the Creative Commons Attribution License, which permits unrestricted use, distribution, and reproduction in any medium, provided the original work is properly cited.

\begin{abstract}
The availability of PV systems is discussed to determine the optimum availability at which standalone PV systems must be designed. Optimization methods and PV systems software, such as HOMER and PV.MY, were used for this purpose. Six PV systems with six availability levels were analyzed, in terms of wasted energy, cost of energy, battery usage, and power shortages, using real meteorological data. Results show that PV systems with $99 \%$ availability are recommended, because of their high reliability and favorably wasted energy.
\end{abstract}

\section{Introduction}

Considering that PV systems are clean, environment-friendly, and secure energy sources, PV system installation has played an important role worldwide. However, the drawback of PV systems is their high capital cost, compared to conventional energy sources. Currently, many studies were conducted that focus on the optimization of standalone PV systems, so that the number of PV modules, capacity of storage battery, and capacity of inverter were optimally selected. Standalone PV systems are widely used in remote areas without access to electricity grid. These systems had proven their feasibility, compared with conversional standalone power systems (e.g., diesel generators), especially for remote applications, because of the difficulty in accessing the remote areas and the cost of transportation. However, a PV system must be designed to meet the desired load demand at a defined level of availability [1]

Many sizing works for PV system can be found in the literature. Based on [1], three major PV-system-sizing procedures are available, namely, intuitive, numerical (simulation based), and analytical methods, in addition to some individual methods. However, most of these methods depend on system availability. For example, in [2], a well-completed optimization of PV systems in Algeria was implemented by dividing the regions into four zones using sky clearness index. The optimization of PV systems was based on different levels of system availability and a simulation program which calculates the possible sizes of a PV system at a specific system availability and load demand. Thereafter, the optimum PV system configuration is selected based on system capital cost. In [3], an elegant optimization method for PV system was presented. A PV system mathematical model was developed to optimize its size based on well-defined solar energy data and load demand. The developed model contains models for PV array, storage battery, and charge regulator. However, the optimization considers the combined minimum cost with maximum system availability taking into account the uncertainty in solar energy and the variation in the demanded energy by the load.

The optimization of a PV system was done for three sites in the UK using the sizing curves derivation in [4]. To avoid any load interruption, the PV array size was designed based on the worst monthly average solar energy. As for finding the minimum storage requirement, the same method used in plotting the sizing curves of the PV array was used for the battery. The minimum storage requirement was calculated each year of the used historical data. However, PV array size was calculated based on the worst month method, which may cause oversizing in the PV generator, especially in months having average solar energy higher than the worst month. The considered system availability in this study was $100 \%$. 
In [5], an optimization of a PV system was presented based on long term solar radiation series for UK. In this study, the average of the obtained solar radiation series was calculated and divided in two climatic cycles. One of these climatic cycles contains days with average solar radiation equal to or higher than the calculated overall solar radiation average, whereas other climatic cycles contain days that have average solar radiation lower than the calculated overall average solar radiation. Thereafter, the necessary size of the PV generator and the storage battery was calculated based on all the climatic cycles to construct the general-sizing curve at specific system availability. Finally, the resultant sizing curve was fitted to an exponential function to derive a mathematical formula that can be used to calculate PV system size directly. In [6], a comprehensive sizing of standalone PV systems for Malaysia was presented. A simulation was performed, depending on the energy flow in a PV system [7]. By this simulation, the possible sizes of a PV/battery system at different system availabilities for five main locations were obtained and plotted to establish a mathematical correlation between PV array capacity and system availability and between PV array capacity and storage battery capacity. After calculating the coefficients for each region, the averages of these coefficients were calculated to establish a model for all Malaysia. From the examples of PV system optimization that were given, it can be concluded that the PV systems were designed at different levels of availability of $90 \%$ to $100 \%$.

The main objective of the present paper is to study the effect of system availability on system size and cost to recommend an optimum availability level at which PV systems must be designed.

\section{Standalone PV System Availability}

Each standalone PV system, like any other power systems, has a specific level of availability. This reliability level affects system performance, production, feasibility, and investment [8-14]. According to the Sandia National Laboratory in [15], the availability of a standalone PV system can be defined as the percentage of time at which a power system is capable of meeting the load requirements. The number of hours that the system is available, divided by $8760 \mathrm{~h}$, gives the annual system availability. A system with $95 \%$ availability is expected to meet the load requirement of $8322 \mathrm{~h}$ during an average year for the entire useful life of the system. An annual availability of $99 \%$ means that the system can operate the load for $8672 \mathrm{~h}$ of the $8760 \mathrm{~h}$ [15]. In [16], the PV system availability is defined as the percentage of time at which a PV system is capable of meeting the load requirements.

The availability of a PV system can be described by statistical values. In [17], the availability of PV systems is defined as a statistical value, called loss of load probability (LLP), which is given by

$$
\text { LLP }=\frac{\sum_{i=1}^{8760} \text { EnergyDeficit }_{i}}{\sum_{j=1}^{8760} \text { LoadDemand }_{j}} .
$$

The numerator in (1) is the sum of the energy demanded which the PV system cannot cover in a year's time. On the other hand, the denominator is the sum of the energy demanded in a year's time. After calculating the LLP, the availability $(A)$ of the PV system can be expressed as

$$
A=(1-\mathrm{LLP}) * 100 \% \text {. }
$$

Some researchers used another statistical value to describe the availability of a PV system, namely, loss of power supply probability (LOSP). In $[18,19]$, LOSP is described as a probability function,

$$
f_{c}=\mathrm{SOC}(t) \leq \mathrm{SOC}_{\min } ; \quad \text { for } \longrightarrow t \leq T,
$$

where $f_{c}$ is the probability that the state of charge at any accumulative time $t$ within the time period $T$ will be equal to or less than the minimum permissible level $\left(\mathrm{SOC}_{\min }\right)$.

According to this formula, the availability of a PV system can be calculated as

$$
A=\left(1-f_{c}\right) * 100 \% .
$$

However, increasing PV system availability increases the size of the system and, consequently, the capital cost of the system. In [20], the effect of the availability of PV system on PV array cost is deeply studied. According to [20], the system size and cost increased rapidly while trying to obtain the last few percentages of availability. The relation between PV array cost (size) and system availability was almost liner until $80 \%$, at which it became logarithmic thereafter. In addition, the Sandia National Laboratory, in [15], illustrated the relation between the peak sunshine hours of the system and the needed storage capacity for the system at two levels of system availability. According to [15], the storage needed from a PV system that has $99 \%$ availability is higher than that from a PV system with $95 \%$ availability. Moreover, the difference between the needed storage capacities becomes much higher as the number of peak sunshine hours becomes lower than 4 .

Based on that, increasing availability of the PV system increased the size of the PV array and the needed storage capacity. On these bases, knowing the optimum availability at which the PV system must be designed is important. In [15], two levels of availability are recommended: $95 \%$ and $99 \%$. However, these authors stated that the $95 \%$ availability is more recommended. Meanwhile, in [20], it is suggested that the nature of the load of the PV system determines its availability. For example, telecommunication repeater stations will be considered as a critical load. Thus, 99\% availability is demanded, whereas other noncritical loads can be designed based on $95 \%$ availability. In [2], the availability of PV systems in the range of $90 \%$ to $100 \%$ is recommended. Meanwhile, in [3], the availability of PV systems in the range of $92 \%$ to $99.9 \%$ is recommended. In [4], it is recommended that PV systems must be designed at $100 \%$ availability. In addition, in [5], it is suggested that PV system availability must be higher than $95 \%$ and that an LLP value of zero cannot be assigned. In [6], the PV system availability in the range of $95 \%$ to $99 \%$ is recommended, whereas a $98 \%$ availability of PV system is recommended in [7]. Finally, the HOMER software, which is a widely used PV system optimization tool, designs standalone PV systems at 100\% availability. 
TABLE 1: Designed PV systems specification.

\begin{tabular}{|c|c|c|c|c|c|c|c|}
\hline$A$ & $C_{A}(\mathrm{kWp})$ & $C_{B}(\mathrm{Ah} / 12 \mathrm{~V})$ & $E_{\mathrm{PV}}(\mathrm{kWh})$ & LOLH & $E_{D}(\mathrm{kWh})$ & $\mathrm{CoE}(\$ / \mathrm{kWh})$ & $\mathrm{SOC}_{80 \%}$ \\
\hline $100 \%$ & 4.3 & 1316 & 6882 & 0 & 4645 & 0.6 & 7881 \\
\hline $99 \%$ & 2.5 & 324 & 4000 & 199 & 1789 & 0.27 & 2748 \\
\hline $98 \%$ & 2.3 & 270 & 3681 & 386 & 1491 & 0.25 & 2595 \\
\hline $97 \%$ & 2.2 & 260 & 3521 & 661 & 1368 & 0.24 & 2502 \\
\hline $96 \%$ & 2.1 & 250 & 3361 & 736 & 1217 & 0.23 & 2416 \\
\hline $95 \%$ & 2 & 240 & 3201 & 972 & 1090 & 0.22 & 2341 \\
\hline
\end{tabular}

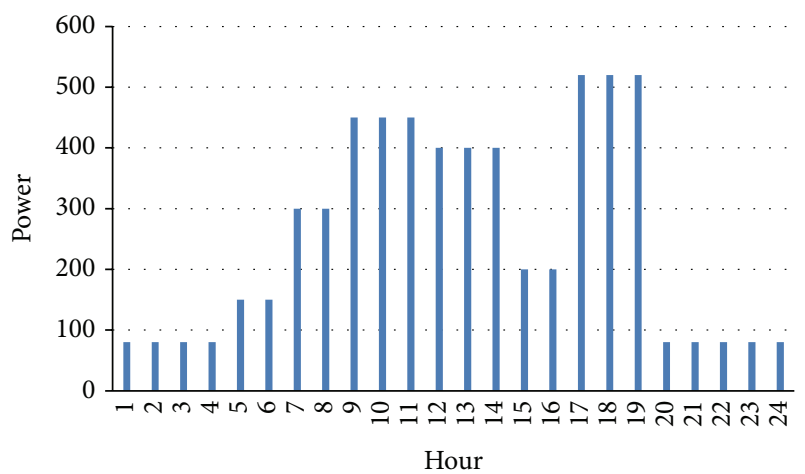

FIGURE 1: Simulated load demand.

On these bases, the availability of PV systems is mostly recommended in the range of $95 \%$ to $100 \%$. However, an exact availability level is not yet determined even by the present study. A more specific availability level must be defined among the availability levels that are in the range of $95 \%$ to $100 \%$. In the next section, a brief analysis of a PV system designed at six availability levels is performed to try to find the optimum availability at which PV systems must be designed.

\section{Searching for the Optimum PV System Availability}

In this section, a brief analysis of a PV system designed at six availability levels (95\%, 96\%, 97\%, 98\%, 99\%, and 100\%) is performed to find the best system availability at which PV systems must be designed. Figure 1 shows the used load demand. The total load demand was $6.135 \mathrm{kWh} /$ day with a maximum power of $0.52 \mathrm{~kW}$. The average load power was $0.255 \mathrm{~kW}$ and the load factor was $49 \%$.

In this section, the method proposed by [6] was used to design the PV system at different availability levels. In addition, the tool presented in [21] was used to simulate these systems using hourly solar radiation and ambient temperature records for Kuala Lumpur City, Malaysia. The proposed method and the HOMER software were used to design the PV system at $100 \%$ availability. Then, the methods proposed in $[6,21]$ were used to design and analyze the designed PV systems

According to HOMER, a PV system with a $4 \mathrm{kWp}$ PV array and $1500 \mathrm{Ah} / 12 \mathrm{~V}$ storage battery is needed to meet the desired load demand at zero loss of load probability (100\% availability). On the other hand, for the method in [6], a PV system with $4.3 \mathrm{kWp}$ and $1316 \mathrm{Ah} / 12 \mathrm{~V}$ storage battery is needed to meet the desired load demand. The difference between the result given by HOMER and that by the proposed method is attributed to two reasons: the nature of the meteorological variable used and the specification assumption of the device. As for the former, the method in [6] used real hourly meteorological data, whereas HOMER used monthly averages and converted it into hourly data using embedded models. As for the latter, many differences exist in the defined specifications for the modeled devices, such as conversion efficiency of the PV module, charging efficiency of the battery, and other factors.

Table 1 shows the specifications and statistics of six PV systems designed at six availability levels. The table shows the availability level $(A), \mathrm{PV}$ array capacity $\left(C_{A}\right)$, storage battery capacity $\left(C_{B}\right)$, energy generated by the PV array in a year's time $\left(E_{\mathrm{PV}}\right)$, number of loss load hours (LOLH), damped energy $\left(E_{D}\right)$, cost of energy generated by the PV system $(\mathrm{CoE})$, and number of hours in the year that the SOC of the battery was higher than $80 \%\left(\mathrm{SOC}_{80 \%}\right)$. As for LOLH, the simulation counted each hour within which an energy deficit occurs, despite the fact that some of the hourly demands can be partially covered.

From the table, the system with $100 \%$ availability consisted of a $4.3 \mathrm{kWp}$ PV array and a $1316 \mathrm{Ah} / 12 \mathrm{~V}$ storage unit. The system generated $6882 \mathrm{kWh}$ per year, whereas $4645 \mathrm{kWh}$ was damped, which means that $67.5 \%$ of the energy generated was wasted. The cost of energy generated by such a system is $0.6 \mathrm{USD} / \mathrm{kWh}$. In addition, the battery SOC was higher than $80 \%$ in about $89.9 \%$ of a year's time, which indicates that the battery was not the kind used during a year's time.

As for the system with $99 \%$ availability, a $2.5 \mathrm{kWp}$ PV array and a $324 \mathrm{Ah} / 12 \mathrm{~V}$ storage battery are the recommended energy source sizes. In a year's time, $4000 \mathrm{kWh}$ was generated, whereas $45 \%$ of this energy was damped. The cost of the energy generated by the system is $0.27 \mathrm{USD} / \mathrm{kWh}$. The battery SOC in $31 \%$ of a year's time was higher than $80 \%$, which means that the battery was well used compared with the previous case. The number of hours at which the system cannot meet the load demand was 199, which translates to $2.2 \%$ of a year's time.

As for the remaining system options, the performances of these systems were close to each other, whereas the needed $\mathrm{PV}$ array and battery capacity were in the range of $2.3 \mathrm{kWp}$ to $2 \mathrm{kWp}$ and $270 \mathrm{Ah} / 12 \mathrm{~V}$ to $240 \mathrm{Ah} / 12 \mathrm{~V}$. The generated 


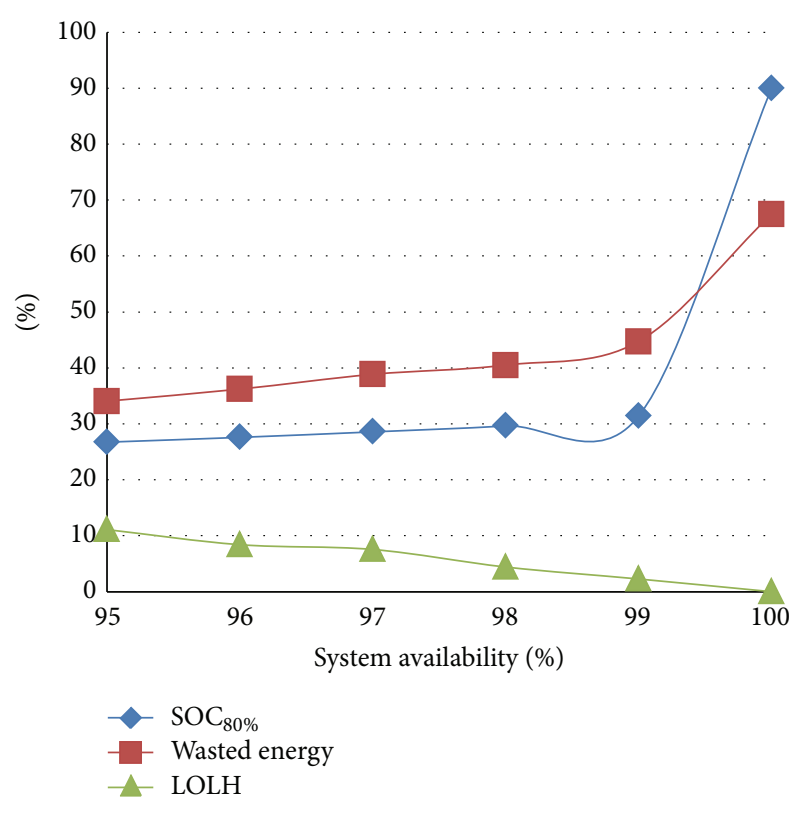

FIgURE 2: PV systems comparison.

energy was in the range of $3201 \mathrm{kWh} /$ year to $3681 \mathrm{kWh} /$ year, whereas the percentage damped energy was in the range of $34 \%$ to $40 \%$. On the other hand, the cost of the energy generated by these systems was in the range of $0.22 \mathrm{USD} / \mathrm{kWh}$ to $0.25 \mathrm{USD} / \mathrm{kWh}$, whereas the percentage of the days within which the battery SOC was higher than $80 \%$ was in the range of $28 \%$ to $30 \%$. The LOLH values of these systems were in the range of $4.4 \%$ to $11.1 \%$, which are high values, especially, compared with the previous systems.

Figure 2 shows a comparison among these systems in terms of wasted energy (damped energy-to-generated energy), battery usage ( $\mathrm{SOC}_{80 \%}$ to the number of hours in a year's time), and LOLH percentage (LOLH to the number of hours in a year's time). The figure shows that systems with availability in the range of $99 \%$ to $95 \%$ had almost similar battery usages. Hence, systems with $98 \%$ to $99 \%$ availability are recommended in this regard. As for LOLH, systems with availability values in the range of 98 to 100 are recommended. Finally, systems with availability values in the range of $97 \%$ to $98 \%$ are recommended, in terms of wasted energy. On the basis of these results, systems with availability values of $98 \%$ and $99 \%$ are most recommended.

Referring to the CoE in Table 1, it is noted that, by using the system with $99 \%$ availability, the supplier lost $298 \mathrm{kWh} /$ per year in damped energy, compared with the system with $98 \%$ availability. Moreover, the generation of energy costs the supplier 0.02 USD per kWh more, compared with the system with $98 \%$ availability. On the other hand, the LOLH value increased by $187 \mathrm{~h}$ in the system with $98 \%$ availability, compared with the system with $99 \%$ availability. Thus, despite the fact that the system with $98 \%$ availability was cheaper in terms of unit cost and damped energy, it is less reliable compared with the system with $99 \%$ availability. Upon this basis, PV systems with 99\% availability are recommended due to their high reliability and favorable running costs.

\section{Conclusion}

Optimum PV system availability was studied and presented in this paper. Six PV systems with different reliability levels were studied using solar energy and ambient temperature records for Kuala Lumpur City, Malaysia. The performance analysis was in terms of wasted energy, cost of energy, battery usage, and power shortages using real meteorological data. The results show that PV systems with $99 \%$ availability are recommended due to their high reliability and favorably wasted energy.

\section{Conflict of Interests}

The authors declare that there is no conflict of interests regarding the publication of this paper.

\section{Acknowledgments}

This work is supported by Lakeside Labs, Klagenfurt, Austria, and funded by the European Regional Development Fund (ERDF) and the Carinthian Economic Promotion Fund (KWF) under Grant KWF 20214|23743|35470 (Project MONERGY) and 20214|22935|34445 (Project Smart Microgrid). The authors would like to thank Lizzie Dawes for proofreading the paper.

\section{References}

[1] T. Khatib, A. Mohamed, and K. A. Sopian, "A review of photovoltaic systems size optimization techniques," Renewable and Sustainable Reviews, vol. 22, pp. 454-465, 2012.

[2] A. H. Arab, B. A. Driss, R. Amimeur, and E. Lorenzo, "Photovoltaic systems sizing for Algeria," Solar Energy, vol. 54, no. 2, pp. 99-104, 1995.

[3] G. B. Shrestha and L. Goel, "A study on optimal sizing of standalone photovoltaic stations," IEEE Transactions on Energy Conversion, vol. 13, no. 4, pp. 373-378, 1998.

[4] A. Fragaki and T. Markvart, "Stand-alone PV system design: results using a new sizing approach," Renewable Energy, vol. 33, no. 1, pp. 162-167, 2008.

[5] T. Markvart, A. Fragaki, and J. N. Ross, "PV system sizing using observed time series of solar radiation," Solar Energy, vol. 80, no. 1, pp. 46-50, 2006.

[6] T. Khatib, A. Mohamed, K. Sopian, and M. Mahmoud, "A new approach for optimal sizing of standalone photovoltaic systems," International Journal of Photoenergy, vol. 2012, Article ID 391213, 7 pages, 2012.

[7] P. Arun, R. Banerjee, and S. Bandyopadhyay, "Optimum sizing of photovoltaic battery systems incorporating uncertainty through design space approach," Solar Energy, vol. 83, no. 7, pp. 1013-1025, 2009.

[8] P. Zhang, W. Li, S. Li, Y. Wang, and W. Xiao, "Reliability assessment of photovoltaic power systems: review of current status and future perspectives," Applied Energy, vol. 104, pp. 822-833, 2013.

[9] R. Fucci, L. Lancellotti, and C. Privato, "A procedure for assessing the reliability of short circuited concentration photovoltaic systems in outdoor degradation conditions," Microelectronics Reliability, vol. 54, no. 1, pp. 182-187, 2014. 
[10] G. Zini, C. Mangeant, and J. Merten, "Reliability of large-scale grid-connected photovoltaic systems," Renewable Energy, vol. 36, no. 9, pp. 2334-2340, 2011.

[11] R. M. Moharil and P. S. Kulkarni, "Reliability analysis of solar photovoltaic system using hourly mean solar radiation data," Solar Energy, vol. 84, no. 4, pp. 691-702, 2010.

[12] J. K. Kaldellis, P. Koronakis, and K. Kavadias, "Energy balance analysis of a stand-alone photovoltaic system, including variable system reliability impact," Renewable Energy, vol. 29, no. 7, pp. 1161-1180, 2004.

[13] V. Sharma and S. S. Chandel, "Performance and degradation analysis for long term reliability of solar photovoltaic systems: a review," Renewable and Sustainable Energy Reviews, vol. 27, pp. 753-767, 2013.

[14] M. Lee, D. Soto, and V. Modi, "Cost versus reliability sizing strategy for isolated photovoltaic micro-grids in the developing world," Renewable Energy, vol. 69, pp. 16-24, 2014.

[15] Sandia International Laboratory, Standalone Photovoltaic Power Systems, Sandia International Laboratory, Albuquerque, NM, USA, 1995.

[16] T. Ball and V. Risser, "Stand-alone terrestrial photovoltaic power systems," in Proceedings of the 20th IEEE Photovoltaic Specialists Conference, Tutorial Notes, Las Vegas, Nev, USA, 1988.

[17] P. Tsalides and A. Thanailakis, "Loss-of-load probability and related parameters in optimum computer-aided design of stand-alone photovoltaic systems," Solar Cells, vol. 18, no. 2, pp. 115-127, 1986.

[18] E. Ofry and A. Braunstein, “The loss of power supply probability as a technique for designing standalone solar electrical (Photovoltaic) systems," IEEE Transactions on Power Apparatus and Systems, vol. 102, no. 5, pp. 1171-1175, 1983.

[19] I. Abouzahr and R. Ramakumar, "Loss of power supply probability of stand-alone photovoltaic systems: a closed form solution approach," IEEE Transactions on Energy Conversion, vol. 6, no. 1, pp. 1-11, 1991.

[20] S. R. Wenham, M. A. Green, and M. E. Watt, Applied Photovoltaics, Earthscan, London, UK, 2007.

[21] T. Khatib, A. Mohamed, and K. Sopian, "A software tool for optimal sizing of PV systems in Malaysia," Modelling and Simulation in Engineering, vol. 2012, Article ID 969248, 16 pages, 2012. 

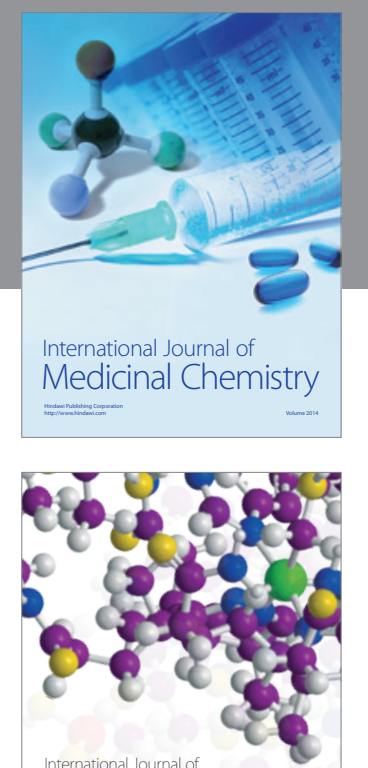

\section{Carbohydrate} Chemistry

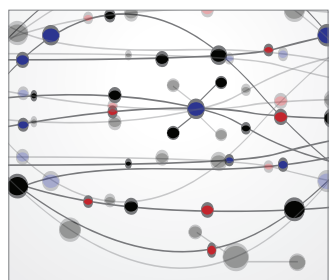

The Scientific World Journal
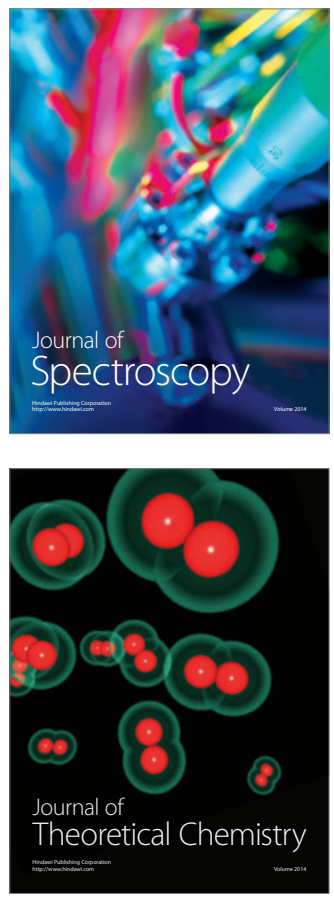
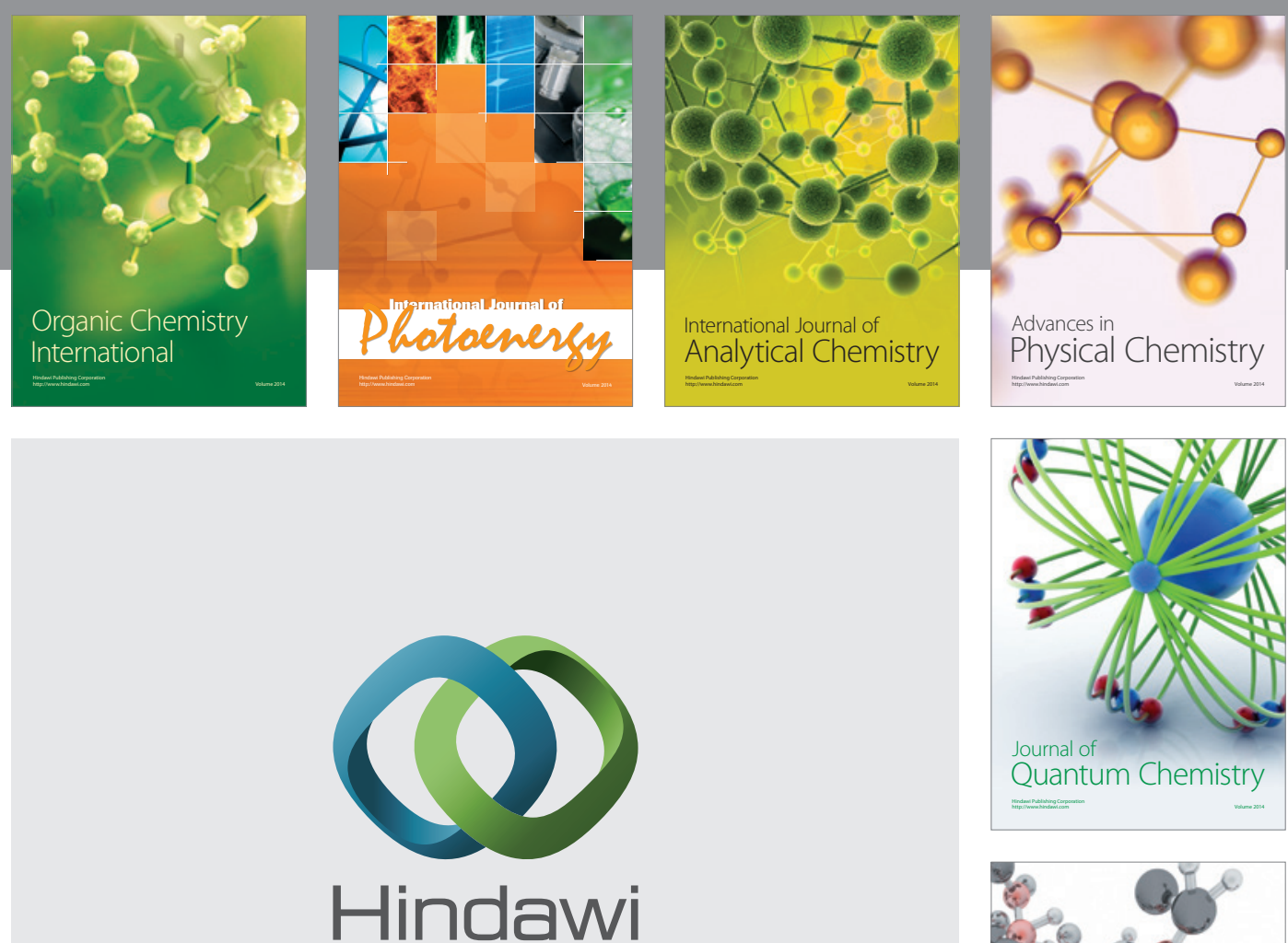

Submit your manuscripts at

http://www.hindawi.com

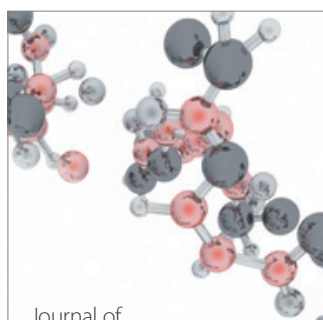

Analytical Methods

in Chemistry

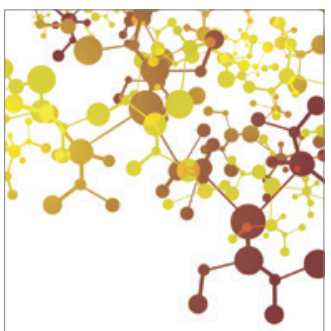

Journal of

Applied Chemistry

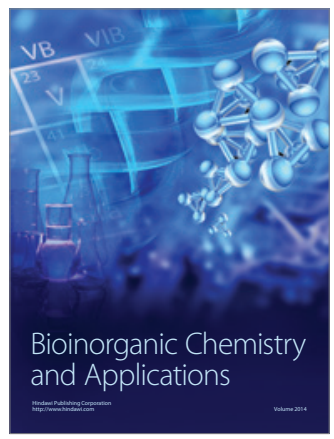

Inorganic Chemistry
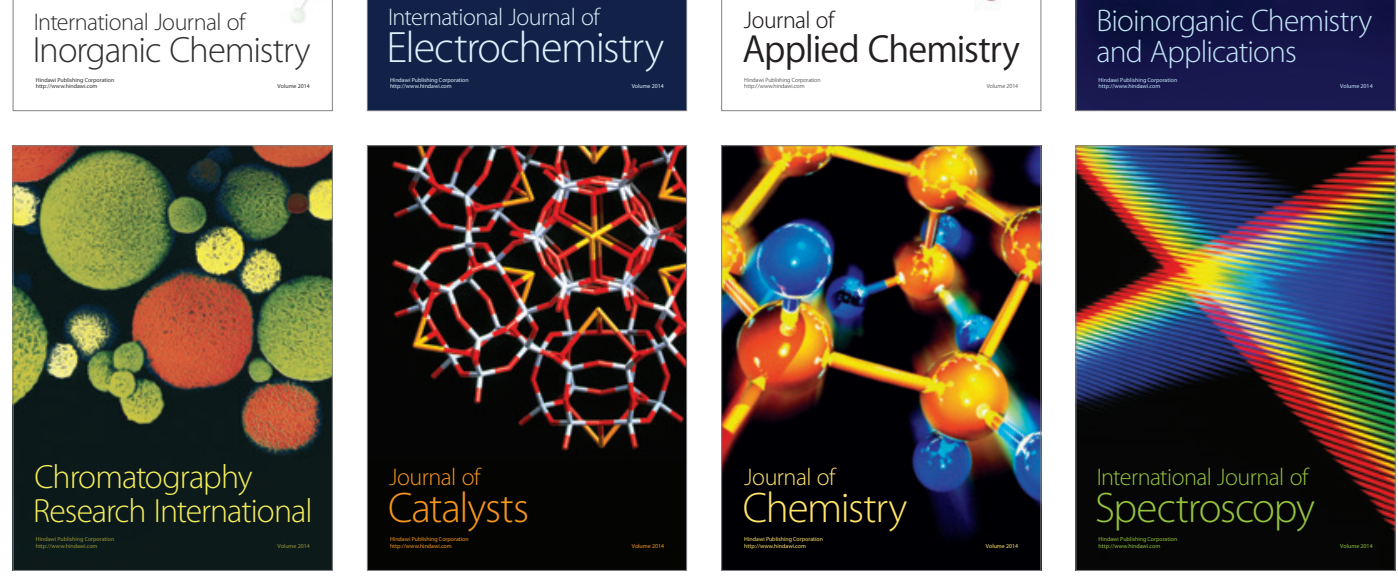